\title{
Application of the Multiple Perspectives Model in an Undergraduate Course*
}

\author{
Célio Gonçalo Marques ${ }^{1}$ and Ana Amélia A. Carvalho² \\ ${ }^{1}$ Instituto Politécnico de Tomar, Estrada da Serra, Quinta do Contador, \\ 2300-313 Tomar, Portugal \\ celiomarques@ipt.pt \\ ${ }^{2}$ Universidade do Minho, Campus de Gualtar, \\ 4710-057 Braga, Portugal \\ aac@ie.uminho.pt
}

\begin{abstract}
To meet the needs of contemporary society it is crucial that instructors strive to find and employ methodologies that enhance active learning. This paper presents a blended-learning model based on the Cognitive Flexibility Theory, called "Multiple Perspectives Model", and describes students' reactions to its application in a course module of the undergraduate programme in Human Resources Management and Organizational Behaviour offered by the Management School of the Polytechnic Institute of Tomar.
\end{abstract}

Keywords: Higher Education, Blended-Learning, Multiple Perspectives Model.

\section{Introduction}

Contemporary higher education faces a series of challenges that stem from lifelong learning needs, globalization and market expansion as well as the strong development of information technologies such as the learning management systems (LMS), the development of mobile technologies, the growth of Web 2.0 tools and the emergence of interactive and immersive virtual reality tools.

The Internet allows access to learning and training exempt from space and time restrictions, enabling an interactive, learner-centred learning. As Harasim [1] points out, "on-line education is more than a new delivery mode. It is a new learning domain" (p. 62). According to Siemens and Tittenberger [2], during the next decade teaching/learning practices will undergo profound changes as universities adapt to global trends at social, political, technological and educational levels. In the face of this new reality, it is of utmost importance that instructors make every effort to find and use new teaching practices where each student plays a key role in the learning process. In this context, the term blended-learning (or mixed learning) seems to have acquired a new dimension. Garrison and Vaughan [3] refer to blended-learning as "a coherent design approach that openly assesses and integrates the strengths of face-to-face and online learning to address worthwhile educational goals" (p.x). These authors believe that "when blended-learning is well understood and implemented, higher education will be transformed in a way not seen since the expansion of higher education in the

${ }^{*}$ Research in part funded by CIEd, University of Minho. 
late 1940s" (p.x). Blended learning must therefore be considered as being strategically important "in the future of universities, their students and teachers as well as in the widening community of professional education and training" (p.1) [4]. Although there are several combinations of blended-learning, there is no widely accepted model [5]. Combination is selected on a case-to-case basis [6]. Our proposal makes use of the Multiple Perspectives Model [7], which is specially suited for advanced learning.

\section{The Multiple Perspectives Model}

The Multiple Perspectives model is a blended-learning model which integrates a faceto-face component including an introduction to the topic and a tutorial about Moodle, as well as an on-line component based on learning objects structured according to the Multi-Perspectives Learning Objects model (MPLO) and the use of a forum and chat communication tools.

\subsection{Learning Objects}

The origins of the term learning object date back to Wayne Hodgins who in 1994 named the CedMA Working Group as "Learning Architectures, APIs and Learning Objects"[8], [9]. Although there is no consensual definition, it seems to us that this is a resource that can be reused in different learning contexts. Its distribution throughout the various information networks and user friendliness enables its wide dissemination and use by a large number of people, whether they are technological experts or not [10].

This approach is similar to some existing models including object-oriented programming; however, its emergence seems to be associated with the expansion of online teaching and learning. Its adoption is viewed as a strategic option for enterprises and educational establishments, particularly for higher education institutions. The benefits from using this approach are huge both to learners and content development managers/practitioners [11] including reduction of content development costs [11], [12], easier construction of processes and experiences to meet individual or target audience needs [11], [12] and its use across a variety of hardware and software platforms.

A learning object should be regarded as a digital, self-sufficient unit whose learning outcomes and structure are connected with a given learning theory.

\subsection{The Multi-Perspectives Learning Objects Model (MPLO)}

The Multiple Perspectives model focuses on the exploration of cases available in the form of learning objects structured according to the MPLO [13], [14].

The MPLO is based on our previous research regarding the Cognitive Flexibility theory [15], [16], [17], [18], [19]. Findings from those investigations evidenced the importance of knowledge deconstruction through multiple themes or perspectives.

The proposed model applies only to advanced levels of acquisition and to complex knowledge domains, which needs to be analysed from multiple perspectives, points of view or themes. It is important to study the situation (mini-case) as it occurs, allowing the learner to acquire a deep comprehension of the subject matter. This 
approach is context-dependent. It focuses on knowledge application rather than on theoretical aspects.

Each learning object corresponds to a case. It can be a segment of a chapter of a book, a news report, a few frames of a movie, or an event. The case has to be divided into parts (mini-cases). Each mini-case is a small unit that will later be deconstructed or analyzed according to different perspectives.

Once the case is selected, it is important to identify the perspective that will be used in the analysis (deconstruction) of the case (mini-cases). These perspectives can be concepts, theories, points of view, or themes that help the learner understand the situation (mini-case) through different insights. A comment must be written from each perspective that is applied to a mini-case, explaining how this general perspective applies to each particular situation. This is a demanding and timeconsuming task for the instructor. However, all this effort is rewarded by learners' comprehension and flexibility in knowledge transfer to new situations.

Each learning object possesses three components that the learner goes through to acquire a deep comprehension of the case and develop cognitive flexibility.

The first component is the case (fig. 1). The learner has access to the full case. $\mathrm{He} / \mathrm{she}$ has to be familiar with it before starting the deconstruction or analysis process. Some additional information about the case may be provided, which helps the learner to better understand it. The second component presents the perspectives that were selected to analyse the mini-cases. The learner has access to a brief description regarding each perspective to understand its boundaries. References for each perspective are also included. The third component is the deconstruction. This is the most important component. The learner is guided through each mini-case and its multiple perspectives of analysis. He/she views how a situation can be analysed or deconstructed through several perspectives. The learner has to read all comments that explain how each perspective is addressed for each mini-case.

This is a process of knowledge deconstruction and reconstruction. This way, learners develop a deeper understanding regarding the subject under study and improve cognitive flexibility, which is essential to the transfer of knowledge into new situations.

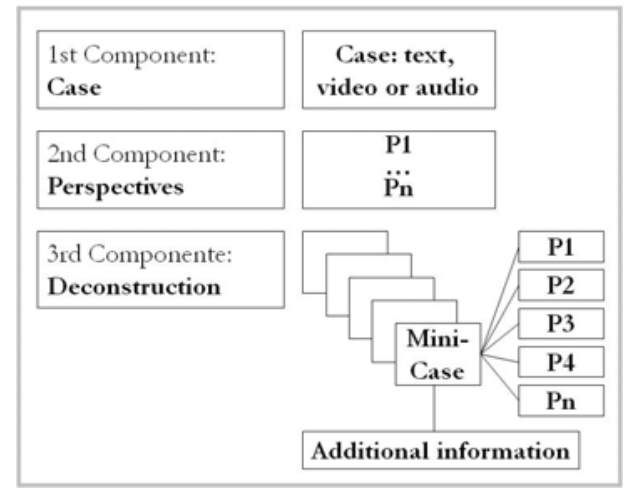

Fig. 1. MPLO model components 


\subsection{Activities Organized according to the Multiple Perspectives Model}

In a course unit or module, several cases can be used which will be made available in the LMS. The Moodle platform and SCORM/AICC are used at the Polytechnic Institute of Tomar (IPT).

First, the learners should read all information regarding the case. To support students' doubts there will be two weekly chat sessions. Using the LMS forum, the instructor will provide questions that will require association within mini-cases that, although apparently different, are approached through the same perspectives.

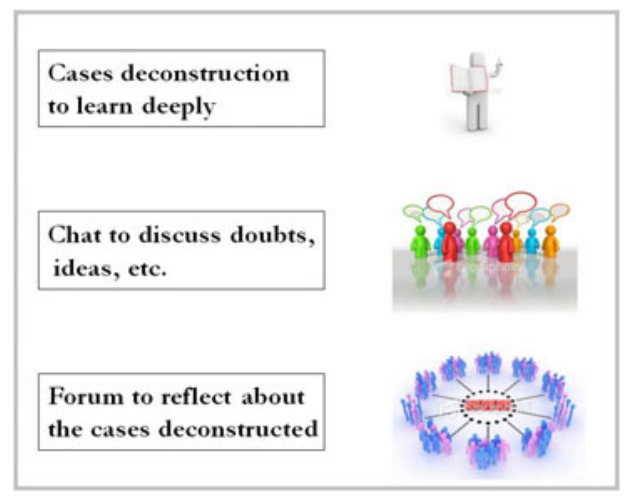

Fig. 2. Multiple Perspectives model components

This is intended to enable learners to have an insight across mini-cases [20]. Once learners have answered the questions, immediate feedback from the instructor is crucial.

This model also presupposes that the instructor guides learners in their selfdirected learning, supporting students within the chat sessions and giving them feedback to their replies to the forum questions.

The instructor may combine several cases to each course module. The advantage is to reuse cases in different courses.

\section{Application of the Multiple Perspectives Model}

In 2009, using a research-action methodology, we applied and validated the Multiple Perspectives Model within higher education [21].

It started with a pilot study held between May and June 2009 intended to check the clarity of tools and instruments to collect data. This study included 34 students attending the Information and Communication Technologies module of the undergraduate programme in Public Administration offered by Tomar Management School. Using the pilot study as a basis, some adjustments to the model and tools have been made.

Our first research-action study started in the beginning of 2009/2010 with the application and validation of the Multiple Perspectives Model to teaching the computer architecture module. Data has been collected using questionnaires, interviews, of LMS (Moodle) and a knowledge test. Table 1 demonstrates the structure of first stage research-action study. 
Table 1. Structure of Study

\begin{tabular}{|c|c|}
\hline Date & Activities \\
\hline Prior to & - Workshop on IPT LMS (Moodle) \\
\hline Module & - Tutorials about Moodle \\
\hline $\begin{array}{l}1^{\text {st }} \text { week: } \\
\text { face-to-face } \\
\text { activities }\end{array}$ & $\begin{array}{l}\text { - Detailed explanation of the module and relevant work plan. } \\
\text { - Learners complete a characterization questionnaire (Moodle); } \\
\text { - Introduction to the computer architecture theme. }\end{array}$ \\
\hline $\begin{array}{l}2^{\text {nd }} \text { week: } \\
\text { on-line activi- } \\
\text { ties }\end{array}$ & $\begin{array}{l}\text { - Definition of the weekly work plan (Moodle); } \\
\text { - Provision of cases } 1 \text { and } 2 \text { (Moodle); } \\
\text { - Provision of a question (1) on cases } 1 \text { and } 2 \text { in the forum (Moodle); } \\
\text { - Two chat sessions (Moodle); } \\
\text { - Feedback from the instructor on answers to question } 1 \text { (Moodle). }\end{array}$ \\
\hline $\begin{array}{l}3^{\text {rd }} \text { week: } \\
\text { on-line activi- } \\
\text { ties }\end{array}$ & $\begin{array}{l}\text { - Definition of the weekly work plan (Moodle); } \\
\text { - Provision of cases } 3 \text { and } 4 \text { (Moodle); } \\
\text { - Provision of a question (2) on cases } 3 \text { and } 4 \text { in the forum (Moodle); } \\
\text { - Two chat sessions (Moodle); } \\
\text { - Feedback from the instructor on answers to question } 2 \text { (Moodle). }\end{array}$ \\
\hline $\begin{array}{l}4^{\text {th }} \text { week: } \\
\text { on-line and } \\
\text { face-to-face } \\
\text { activities }\end{array}$ & $\begin{array}{l}\text { - Learners complete opinion survey on the module (Moodle); } \\
\text { - Knowledge test; } \\
\text { - Final commentary about the module; } \\
\text { - Interviews. }\end{array}$ \\
\hline
\end{tabular}

Prior to module activities, a workshop has been provided to allow learners to familiarise themselves with LMS (Moodle). Three tutorials about Moodle have also been designed through the Jing tool intended for those learners who didn't have the opportunity to attend the workshop.

During the first week there were two face-to-face sessions in order to explain the structure of the module and present the work plan. In these sessions, a characterization questionnaire was completed and learners were introduced to computer architecture.

The second week was run totally on-line. On Sunday, the weekly work plan was supplied, two cases on computer architecture were provided on Moodle (cases 1 and 2) and one question about those two cases was launched which should be answered until Friday (question 1). Two chat sessions occurred during the week and were moderated by the instructor (in a time schedule agreed upon by learners) where they could clarify doubts on the cases and the whole computer architecture. During the weekend, the instructor gave feedback on all answers to question 1. Third week activities were identical to those of the second week with provision of cases 3 and 4 on computer architecture as well as a question related to these two cases (question 2).

During the fourth week, learners completed an opinion survey regarding the module and took a knowledge test. Finally, the instructor provided feedback on the answers. Some students were selected for an interview. 
In the course module, a referendum regarding the most interesting locations of Tomar has been promoted. This promotion aims to make learners feel more comfortable on-line and allow the participants from outside of Tomar to get familiar with the cultural and natural heritage of the city. In addition to this, some performance tips have occasionally been left in the forum about Moodle functionalities and case reading.

\subsection{The Instruments for Data Collection}

Two questionnaires have been used and evaluated within this study: the sample characterization and the opinion survey on the module. Interviews have also been carried out to clarify less consensual points referred to in the opinion survey.

The characterization questionnaire inquired about age, gender, type of registration (ordinary or employed student), number of module enrolments, whether they had a computer or not, whether they had Internet access or not if so, the type and rate of usage of the Internet connection, their ability to use synchronous and asynchronous communication tools and their willingness to use the Internet to perform learning tasks. The participants were also questioned about preferred times for chat sessions.

Furthermore, the survey collected the learners' opinions about the use of the chat and forum, chat duration, its ability in clarifying doubts, and whether students had consulted the bibliographic references suggested in the cases. The learners were also asked to what extent the forum helped them to identify the gaps in their understanding of specific points of the subject matter and facilitated communication between them and the instructor.

They were also inquired as to the importance of the forum as a tool for learning and reflecting on the module, whether feedback helped them participate more in module subjects, whether it helped them recognise gaps in their understanding of specific points of the subject matter, whether they have obtained feedback from the instructor and to what extent it facilitated learning. This survey also asked whether the cases helped the learners understand the subject matter in the module and whether the cases prepared them to solve specific problems as well as whether they liked this new experience and would study further modules on-line. Finally, they were asked about preferred modes of distance learning as well as the positive and negative aspects of the experience and suggestions to improve them.

Both questionnaires were created and made available through Moodle.

For each learner's interview, an individual script has been prepared based on their responses to the opinion questionnaire regarding the module.

\subsection{The Sample}

The sample consisted of 40 students attending the Computer Applications module of the undergraduate programme in Human Resources Management and Organizational Behaviour offered by the Management School of the Polytechnic of Tomar. The vast majority $(70 \%)$ of individuals inquired were female students, ranged from 18 to 59 years old. The average age is approximately 27 and the mode around 19.

Half of the individuals are employed students and $88 \%$ are enrolled for the first time in this course unit. All participants reported having a computer with Internet access, $85 \%$ reported having a laptop, $40 \%$ a desktop, $5 \%$ a PDA and $3 \%$ a netbook. 
Internet access is through wireless broadband (65\%), ADSL (30\%), cable network $(10 \%)$ and $\mathrm{Wi}-\mathrm{Fi}$ access spots within the student residences.

Most participants reported connecting to the Internet every day $(75 \%)$ and the remainder almost every day.

Participants also reported using different Internet tools and services such as e-mail, chat and wikis. The chat is used daily by $55 \%$ of the individuals, $30 \%$ used it two to three times a week, $13 \%$ once a week and $2 \%$ hardly used it. Forums are less used than chat: $7 \%$ reported participating in forums on a daily basis, $10 \%$ weekly, $13 \%$ occasionally, $25 \%$ hardly ever and $45 \%$ never.

When questioned whether they would study further modules through an on-line platform, 48\% of the individuals answered "Yes, definitely", 50\% "Yes" and 20\% didn't know.

\subsection{The Presentation and Analysis of Results}

Results provided by Moodle as well as the participants regarding the use of the forum, chat and case reading are provided hereafter.

Four cases have been provided to participants. Most participants (80\%) analysed four cases, $5 \%$ three cases, $5 \%$ two cases, $5 \%$ one case and $5 \%$ no cases. The suggested bibliography was consulted by $67 \%$ of the participants. Most of those who reported not having consulted it (70\%) referred that they didn't have time to do so, $15 \%$ didn't consider it as being important and the other $15 \%$ consulted other bibliographies.

In the first chat session, $58 \%$ of the individuals participated, $6 \%$ in the second, $60 \%$ in the third and $75 \%$ in the fourth (Table 2). The number of interventions varied between 215 and 330. Individuals who did not participate in chat sessions invoked professional motives, praxe commitments, computer and Internet problems, family problems, care of his/her baby daughter and lack of doubts.

Table 2. Chat participation $(n=40)$

\begin{tabular}{ccc}
\hline Chat session & Participation (\%). & $\begin{array}{l}\text { Number of } \\
\text { Interventions (f) }\end{array}$ \\
\hline $1^{\text {st }}$ Session & 58 & 215 \\
$2^{\text {nd }}$ Session & 55 & 316 \\
$3^{\text {rd }}$ Session & 60 & 298 \\
$4^{\text {th }}$ Session & 75 & 330 \\
\hline
\end{tabular}

The punctuality rate reported in the first session was low, registering $35 \%$. In order to solve this problem, we posed a question during the opening session and advertised the name of the first student to provide the right answer in the forum as well as the names of those who participated in the forum referencing the most punctual ones from the second session onwards. In the second session there was a slight increase $(46 \%)$, but it still did not reach $50 \%$ because students did not know about the implementation of this novelty. In the third session, however, the percentage of punctual students increased to $80 \%$ and in the fourth session it rose even more to $83 \%$.

We verified that $85 \%$ answered two questions, $10 \%$ one and $5 \%$ none (Table 3 ). Lack of time and the fact that they found it irrelevant were invoked by the latter of students as grounds for not providing a response. 
Table 3. Forum participation $(n=40)$

\begin{tabular}{lcc}
\hline Questions & Answers & $(\%)$ \\
\hline 2 Questions & (f) & 85 \\
1 Question & 34 & 10 \\
None & 4 & 5 \\
\hline
\end{tabular}

\subsubsection{Reactions to the Forum and Chat}

Most individuals (53\%) found the forum very user-friendly, $40 \%$ found it easy to use and $7 \%$ found it neither easy nor difficult to use.

The chat was described as being very user-friendly by $50 \%$ of the individuals. Furthermore, $43 \%$ found it easy to use and two individuals found it neither easy nor difficult.

Most individuals $(80 \%)$ found that the ideal duration for chat sessions was 1 hour. Three individuals, however, found it to be insufficient. Some individuals (13\%) had the opportunity to clarify a great number of doubts regarding the subject matter studied in chat sessions, 34\% answered many questions, $40 \%$ answered some questions and $10 \%$ answered a few. One individual reported not having answered any question.

It was verified that $57 \%$ of the individuals fully agreed with the fact that chat sessions helped them realise that there were gaps in their understanding of specific aspects of the subject matter, $40 \%$ agreed partially and 3\% did not know. Most individuals $(80 \%)$ strongly agreed that the use of the chat facilitated student-instructor communication, $17 \%$ partially agreed and $3 \%$ did not know.

When questioned about whether detracting from focus in chat sessions was frequent, $13 \%$ of the respondents reported strongly disagreeing, 17\% partially disagreeing, $7 \%$ partially agreeing and 3\% strongly agreeing. The majority of individuals $(60 \%)$ did not know.

Most respondents (74\%) fully agreed that the forum is a very important tool in discussing module related topics, the remainder partially agree.

It was observed that $68 \%$ of the individuals fully agreed that forum questions contributed to a greater involvement in computer architecture related subjects, $29 \%$ agreed partially and $3 \%$ did not know.

Very similar figures have been obtained when questioned whether the forum helped them realise that there were gaps in their understanding of specific subject matters in the module. It was observed that $71 \%$ of individuals fully agreed with this idea, $26 \%$ partially agreed and $3 \%$ did not know.

All respondents reported having developed new skills in the forum using the instructor's feedback. It was also expressed that $82 \%$ of the respondents fully agreed that instructor's feedback within the forum has largely contributed to their learning and $18 \%$ partially agreed with this statement.

\subsubsection{Reactions to the On-Line Module}

We realized that $92 \%$ of the respondents consider that cases helped them understand the module subject matters; and they think this is mainly because cases promote a greater involvement within the subject matters (60\%) and they allow different approaches to the problem $(29 \%)$. 
All respondents agreed that cases prepare them better to solve problems. Typical justifications included that cases allow the transfer of knowledge into new situations $(66 \%)$ and different approaches to the same problem $(24 \%)$.

It was verified that $48 \%$ of respondents liked this on-line module very much, $30 \%$ liked it much, 20\% liked it and one individual did not like it. The great majority of respondents $(95 \%)$ were open to study further modules on-line.

When inquired about the preferred type of learning, $88 \%$ answered blendedlearning, $10 \%$ face-to-face learning and $2 \%$ fully on-line learning. These results indicate a clear preference for blended-learning and are probably related to the success of this study and therefore the model applied.

Justifications for blended-learning were that mixed learning is more effective than face-to-face or fully on-line learning $(57 \%)$, it is a more suitable way of conveying knowledge $(29 \%)$, it is a more comfortable method $(11 \%)$ and it is a gateway into the future $(3 \%)$.

When questioned about the positive aspects of the module, $33 \%$ answered that all aspects were positive, $23 \%$ mentioned the communication/collaboration among all the participants, $12 \%$ mentioned the development of useful day-to-day skills, $10 \%$ mentioned the communication between colleagues, another $10 \%$ mentioned general interaction, $7 \%$ of respondents mentioned on-line learning, and 5\% learning how to use chat and forums.

As far as the negative aspects are concerned, $88 \%$ answered that there were no negative aspects, 5\% indicated few chat sessions, another 5\% mentioned the time schedule for chat sessions and one individual referred to the need for more intensive face-to-face pre-learning.

As far as the aspects for improvement are concerned, $83 \%$ of the respondents answered none, $10 \%$ suggested that there should be more chat sessions, $5 \%$ mentioned the time schedule as well as the amount of classes and one respondent expressed that more practical cases should be provided.

\subsubsection{Results Obtained in the Knowledge Test}

Once the on-line activities were completed, participants answered a knowledge test. The mean grade was 11.7 (Table 4). The highest grade was 18.9, the lowest 2.9, and the mode was established at 14.3.

When analysing the grades of the individuals who participated in two chat sessions and answered the forum questions, we find that the mean rises to 13.9 and the lowest grade to 8.6. These students' involvement seems to have a positive impact on learning outcomes.

Table 4. Test results

\begin{tabular}{lcc}
\hline Descriptive statistics & $\begin{array}{l}\text { Module results } \\
(0-20 \text { grade points }) \\
\mathrm{n}=54\end{array}$ & $\begin{array}{l}\text { Results for students who } \\
\text { participated in the chat and the } \\
\text { forum (0-20 grade points) } \\
\mathrm{n}=30\end{array}$ \\
\hline Mean & 11.7 & 13.9 \\
Mode & 14.3 & 14.3 \\
Highest mark & 18.9 & 18.9 \\
Lowest mark & 2.9 & 8.6 \\
\hline
\end{tabular}




\subsubsection{Interviews}

The interviews allowed us to assess some less positive aspects of the module. We selected thirteen students to be interviewed but only ten showed up.

The most addressed topic was the chat room. According to some of the students interviewed, there should be more chat schedules and they should be earlier. Furthermore, some of them found chat sessions a little confusing due to the large number of participants. One of the students also reported having experienced difficulties in finding the questions and where to answer in the forum. For each question a forum was created and the question was asked in the first forum message. The students were asked to create a new message in order to answer the question but many of them answered directly to the message making it difficult to find the question, which was "lost" itself among the answers.

We have observed that the great majority of interviewed students that showed difficulties with the forum and the chat had neither attended the workshop nor watched the help videos.

Those students preferring face-to-face learning rather than mixed learning or fully on-line learning argue that it is easier to clear doubts face-to-face as opposed to on-line.

All these aspects will be taken into account in a new research-action cycle.

\section{Conclusions}

Blended-learning may be an answer to meet some of the challenges facing higher education. It meets several needs of contemporary students such as time and space flexibility, it provides new possibilities in project-based learning and allows one to develop cross competencies such as problem analysis and resolution.

The Multiple Perspectives model is a blended-learning model proposal for the development of advanced skills based on the Cognitive Flexibility Theory. This model focuses on the use of learning objects and communication tools of the LMS. Its use in the course Computer Applications of the Human Resources Management and Organizational Behaviour programme produced favourable results and was well accepted among students, which makes us believe that it may be a credible option for all teachers wishing to implement blended learning in their courses.

However, the opinion questionnaire and interviews showed that some adjustments still need to be made. In the next application of the model, chat sessions will be limited to 15 users and subject to prior Moodle registration by means of a wiki. Due to this limitation, the number of chat sessions will increase which will enable us to provide afternoon and evening sessions, thus meeting the desire of all students. A contingency plan will be created to cope with possible delays or absences in chat sessions. Most features will be maintained such as the initial chat question, advertising the name of the first student to give the right answer, the participants in that session as well, and the most punctual ones.

Case questions will start to be written in the forum title for easier tracking. In addition to this, a tutorial will be created using Jing software where students will be able to learn how to use the forum to answer the question. 
The final comment will made available in podcast format, thus allowing more students to access the comment and listen to it as they wish.

The possibility of implementing chatbots for generic questions on how LMS works as well as the use of social bookmarking tools will also be considered. We think this sort of tools may contribute to the development of an on-line learning community stimulated by the use of chat. Ensuring that the students familiarise themselves with the LMS prior to module, either through the workshop or the videos, is also crucial.

\section{References}

1. Harasim, L.M.: On-line Education: A New Domain. In: Mason, R.D., Kaye, A.R. (eds.) Mindweave: Communication, Computers and Distance Education. Pergamon Press, Oxford (1989)

2. Siemens, G., Tittenberger, P.: Handbook of Emerging Technologies for Learning (2009), http: / / umanitoba.ca/learning_technologies/cetl/HETL.pdf

3. Garrison, D.R., Vaughan, N.D.: Blended Learning in Higher Education. Framework, Principles and Guidelines. Jossey-Bass, San Francisco (2008)

4. Stacey, E., Gerbic, P.: Introduction to Blended Learning Practices. In: Stacey, E., Gerbic, P. (eds.) Effective Blended Learning Practices: Evidence-Based in Perspectives in ICTFacilitated Education, pp. 1-19. IGI Global, Hershey (2009)

5. Bersin, J.: The Blended Learning Book: Best Practises, Proven Methodologies, and Lessons Learned. Wiley, San Francisco (2004)

6. Beer, M., Mason, R.B.: Using a Blended Approach to Facilitate Postgraduate Supervision. Innovations in Education and Teaching International 46(2), 213-226 (2009)

7. Carvalho, A.A.A.: O Modelo Múltiplas Perspectivas: Uma Proposta para o Ensino Online. Lição das Provas de Agregação. Universidade do Minho, Braga (2009)

8. Wiley, D.A.: Connecting Learning Objects to Instructional Design Theory: A Definition, a Metaphor, and a Taxonomy. In: Wiley, D.A. (ed.) The Instructional Use of Learning Objects: Online Version (2000), http://reusability.org/read/chapters/ wiley.doc

9. Polsani, P.R.: Use and Abuse of Reusable Learning Objects. Journal of Digital Information 3(4) (2003)

10. Marques, C.G.C., Carvalho, A.A.A.: A Pertinência dos Metadados nos Objectos de Aprendizagem. In: Dias, P., Freitas, C.V., Silva, B., Osório, A., Ramos, A. (Orgs.) Challenges 2007, pp. 432-443. Universidade do Minho, Braga (2007)

11. Shepherd, C.: Objects of Interest, TACTIX, Features, Fastrak Consulting (2000),

http: //www. fastrak-consulting.co.uk/tactix/features /

objects/objects.htm

12. Nurmi, S., Jaakkola, T.: Problems Underlying the Learning Object Approach. E-Learning News 2(1) (2006)

13. Carvalho, A.A.A.: A Model to Structure Learning Objects: MPLO (Multiple-Perspectives Learning Objects). In: Abbott, C., Lustigova, Z. (eds.) ITET 2007 - Information Technology for Education and Training, pp. 6-15. ETIC Prague, Prague, (2007)

14. Carvalho, A.A.A.: Looking for a Model to structure Learning Objects: MPLO (MultiplePerspectives Learning Objects). In: Bastiaens, T., Carliner, S. (eds.) Proceedings of ELearn 2007 World Conference on E-Learning in Corporate, Government, Healthcare, \& Higher Education, pp. 37-45. AACE, Chesapeake, VA (2007) 
15. Carvalho, A.A.A., Dias, P.: Hypermedia Environment Using a Case-based Approach to Foster the Acquisition of Complex Knowledge. In: Muldner, T., Reeves, T.C. (eds.) EDMedia/ED-Telecom 1997, Proceedings of the Conferences on Educational Multimedia/Hypermedia and Telecommunications, pp. 142-149. AACE, Charlottesville, vol. I (1997)

16. Carvalho, A.A.A.: How to Develop Cognitive Flexibility in a Web Course. In: Crawford, M., Simonson, M. (eds.) 23rd Annual Proceedings of AECT 2000, pp. 53-60. Nova Southeastern University, North Miami Beach (2000)

17. Carvalho, A.A., Moreira, A.: Criss-crossing Cognitive Flexibility Theory based Research in Portugal: An Overview. Interactive Educational Multimedia 11, 1-26 (2005)

18. Carvalho, A.A.A., Pereira, V.: A Web-based learning platform to promote cognitive flexibility through deconstruction and reflection. In: Nall, J., Robson, R. (eds.) E-Learn $2004-$ World Conference on E-Learning in Corporate, Government, Healthcare, \& Higher Education, pp. 1120-1126. Association for the Advancement of Computing in Education, Norfolk (2004)

19. Marques, C.G.C., Carvalho, A.A.A.: O Fórum como Meio de Reflexão na Aprendizagem do Módulo de Arquitectura de Computadores. In: Mendes, A., Pereira, I., Costa, R. (eds.) SIIE 2005. Instituto Politécnico de Leiria, Leiria (2005)

20. Spiro, R., Jehng, J.-C.: Cognitive Flexibility and Hypertext: Theory and Technology for the Non-linear and Multidimensional Traversal of Complex Subject Matter. In: Nix, D., Spiro, R. (eds.) Cognition, Education and Multimedia: Exploring Ideas in High Technology, pp. 163-205. Lawrence Erlbaum Associates, Hillsdale (1990)

21. McNiff, J., Lomax, P., Whitehead, J.: You and Your Action Research Project. Routledge, London (1996) 